\title{
Comparative Study of Modulation-Based Individual Inverter Techniques for Direct and Inverse by using Star-Connection Induction Motor in Extra Low Voltage Application
}

\author{
Ardhia Wishnuprakasa, Era Purwanto, Novie Ayub Windarko \\ Electric Drive Laboratory, Electronics Engineering Polytechnic Institute of Surabaya \\ ITS Highway, ITS Campus of Sukolilo, Surabaya 60111, Indonesia \\ E-mail: ardhia@pasca.student.pens.ac.id;era@pens.ac.id;ayub@pens.ac.id
}

\begin{abstract}
In this study, the IEEE 519 Standard as a basis benchmarking for voltage $\left(\mathrm{THD}_{\mathrm{V}}\right)$ and current $\left(\mathrm{THD}_{\mathrm{I}}\right)$ in draft performance. Comparative Study based onthree-techniques of 2-Level Converter (2LC) by using a Star-Connection Induction Motor (Y-CIM) in ExtraLow Voltage (ELV) Configuration.For the detail explanation, a primary inverter as Direct-Inverterby $\mathrm{PWM}_{\text {direct }}(\mathrm{PWM})$ degreesand asecondary inverter as Inverse-Inverterby $\mathrm{PWM}_{\text {inverse }}(\mathrm{PWM}+\mathrm{PI})$ degrees. It tends a modified algorithm,for eachof SPWM in six rules, and FHIPWM in $5^{\text {th }}$ harmonics Injectedin standard modulation as the purpose for the Open-Ends of Pre-Dual Inverter in Decoupled SPWM for twelve rules, and Decoupled FHIPWM in combination of $5^{\text {th }}$ harmonics Injectedin combination of two-standard-modulation. Those techniques are the purpose of two-inverter combination, which namelythe Equal Direct-Inverse (EDI) algorithmproduct of prototyping in similarities. The observation is restricted in voltage scope between Simulation by using Power Simulator (PSIM)and Application by using Microcontroller ARM STM32F4 Discovery.
\end{abstract}

Keywords: Direct Inverter, Inverse Inverter, SPWM, FHIPWM.

\section{INTRODUCTION}

In Engineering Technology, theExperimental and Analysis as a kick starter such as applicationtowardthe multilevel inverter fault precaution. For example, the First Inverter and the Second Inverter in Prototyping of PreDual Inverter scheme. For individually, the standalone mode hasseveral techniques such as Sinusoidal (SPWM), and Selective Harmonic Elimination (SHEPWM) which in star-connection Induction Motor (Y-CIM) of each converter [1].In addition, the same configuration such as power supply rating of Programmable Power Spupply, instrument device of ARM STM32F4 Discovery [2], and the induction motor load in three-phases system. One of them, the Inverter with modified THIPWM [3] treat as benchmarking in measurement in the mutual condition. In advance, Evaluation starts from 
Design and Comparison of each inverter to ensure this research for validated by Practical Application and completely done toward converter combination [4]. For the reason, Dual Inverter scheme compensate in working properly by correction of Practical Application, so the Experimental in progress by using comparison has been proposed in [5], but our project is through the Experimental Application. Thus, an arrangement of Rules and Regulations [6], [7] by concerning Terms and Conditions[2], [8], [9]from datasheet setsup. Furthermore, Rules and Regulations tends a policy by observation. Of course, that are for the integrationmatter which the solution in supply system of Extra Low Voltage(ELV) application( $\mathrm{V}_{\mathrm{rms}}<50$ Volt) based on the Institution of Engineering \& Technology (IET) and the International Electrotechnical Commission (IEC)asrules and regulations in the category of low risk [6] for avoiding damage.The trial and error treatments, those for the future work in [1] for an Open-End Winding system (OEWSys) of the Dual scheme. Also, supply system of Equal Direct-Inverse (EDI) by Power Simulator (PSIM) by using IEEE 519 standardization [7] for THD result benchmark with the dataset.

\section{RELATED WORKS}

Many variations of several research have been conducted, its result of each investigation depends on high-low switching pattern, and all of them are refer to theseveral publications.

- Ibrahim Et al.,presents simulation investigation between SPWM, THIPWM, and SVPWM techniques. In this research, an SPWM is using the standard six-rules for PWM switching modulation by a comparator to form Sinusoidal waveform of individual inverter.

- Colak Et al., proposed publicationsabout the multilevel inverter control by harmonic mitigation analysis has the $3^{\text {rd }}$ Harmonics Injection (THIPWM) in modified. This method is working on $V_{1} \sin (\omega t)$ and $\left(V_{1} / n\right) \sin (3 \omega t)$, both of them as input to the comparator pairing with a ramp waveforms.

- Shivakumar Et al. and Rao et al. which proposed techique on the fly of Open-End Winding Preparation by the common technique of SVPWM CONTROL, which is using concordia diagram or symmetrical hexagon. It means, the different techniques are dedication in this research.

- Schweizer Et. al. comparison of $2 \mathrm{LC}$ and 3LC is have the same proposed technique with a three-phases system is used immensely for comparative evaluation. For ELV Regulations, the Simulation result compares by application result for investigation to the authors reflection as references. 


\section{ORIGINALITY}

In this comparative study, the proposed technique of rules and regulations by addedextra low voltage (ELV) as terms and conditions.

- Our investigation of three-phases induction motor is used, it tends of six switching devices and discovering a regulation about two pairs set of six-rules as our solution towarddecoupled SPWM for twelve rules.

- After used of THIPWM in related works, weare trying another part for the Selective Harmonic Injection (SHE) in $5^{\text {th }}$ harmonics namely FHIPWM technique as our proposed toward decoupled FHIPWM.

- The two techniques of Decoupled SPWM and Decoupled FHIPWM, both of Simulation by using PSIM and Practical by using ARM Cortex STM32F4 Discovery with inverter hardware for application in ELV for the multilevel purposes.

- In this research, the comparison between SPWM and THIPWM in ELV. Also, the decoupled of them are arranged to be in waveform variying as rules and regulations.

\section{DESIGNING CONCEPT AND BUILDING PROTOTYPE}

Refering to the Comparative Study, one of the essential issues for designing board is the implementation.Thus, a Dual-twoLevel Converter in the Multilevel Inverter is on progress. This purpose is the part of engineering technology to reach investigation which inspired from [2], [8], and [9], fordesired in real condition.
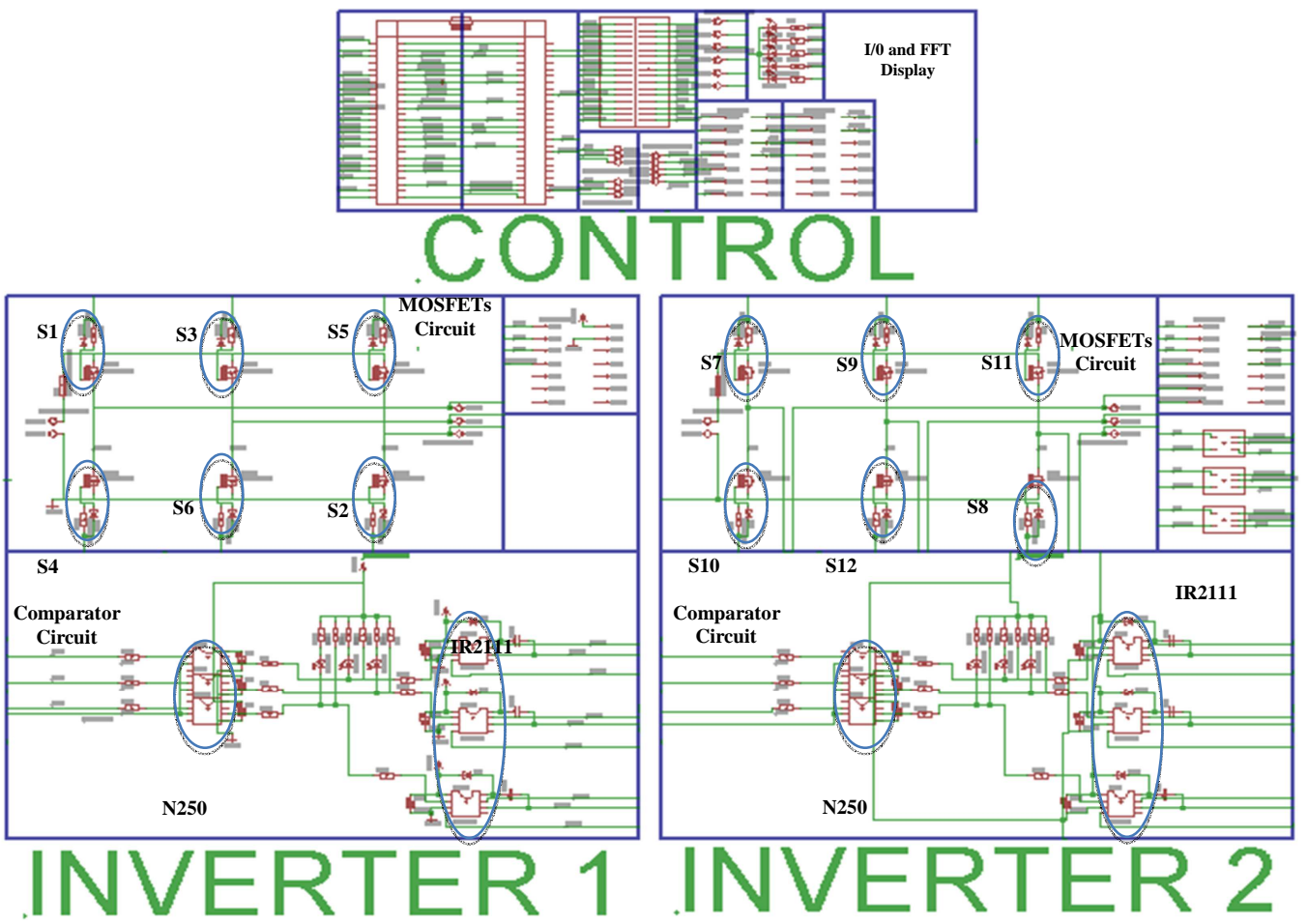

Figure 1. Circuit Design Building of Control, Inverter-1, and Inverter-2 
The schematic is a unity, in which including Control Design Circuit (CDC), Inverter-1 Design Circuit (I1DC) also namely the First Inverter, and Inverter2 Design Circuit (I2DC) also namely the Second Inverter.Schematic of eagle design can be seen in the Figure 1 of the first inverter and the second inverter or the so-called pre-design of dual 2LC.

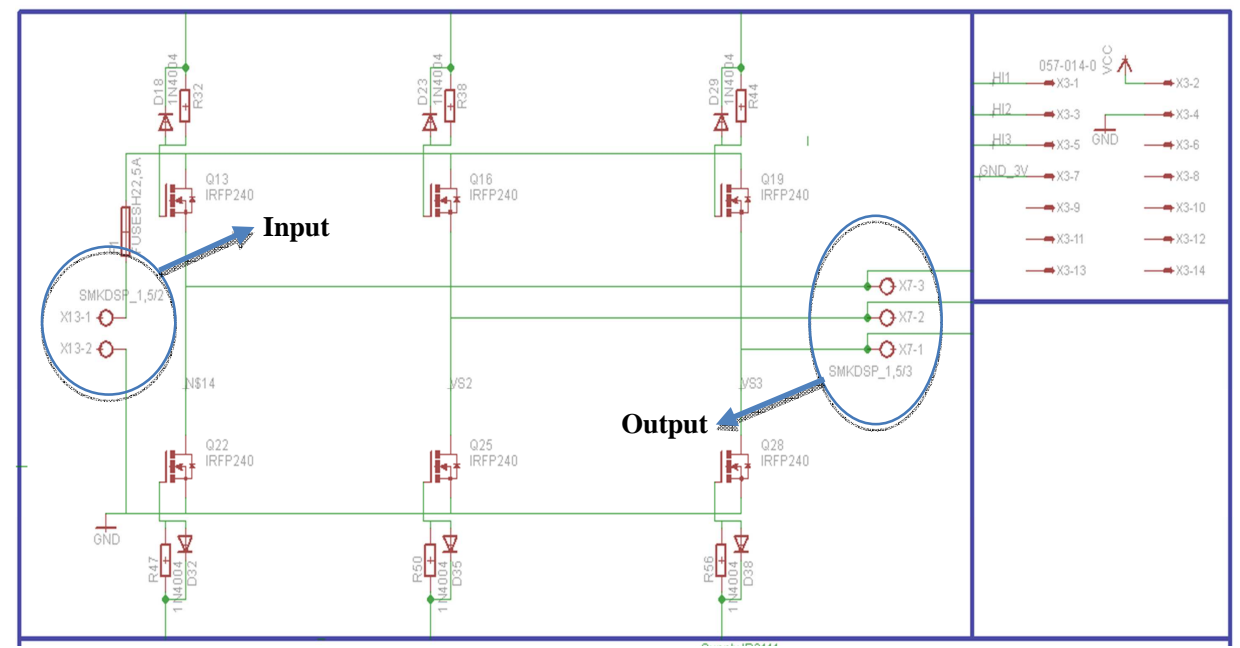

Figure 2. Schematic Design of Power Switching Device Inverter

At first, we are introducing a schematic scheme in eagle software at glance, shown in the Figure 2 in three part of schematic design of circuit planned for acqouintance.The controller $(\mu)$ which using STM32F4 discovery.

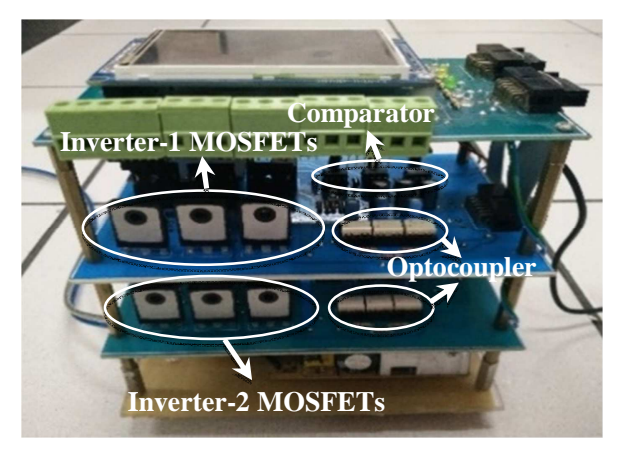

(a)

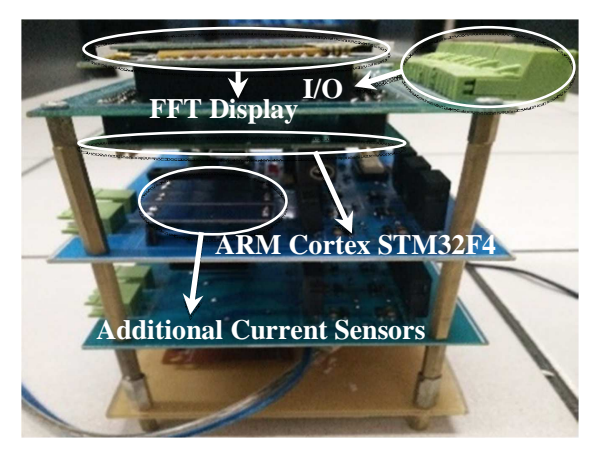

(b)

Figure 3. Physically Apperance of Dual Inverter (a) in front (b) left side

This device in realization would be built in four-floors as shown in Figure 3 as physically appearance. Originally speaking, a Direct Inverter and Inverse Inverter as a counterpart for the immense successor to the Dual Inverter scheme. The physically appearance of dual 2LC in Figure 3 is using FFT

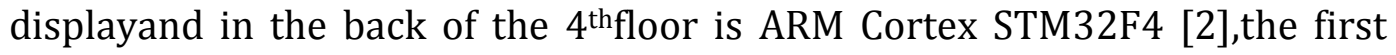
inverter in the $3^{\text {rd }}$ floor, the second inverter in the $2^{\text {nd }}$ floor, and the control component ofeach of the power electronic device. In switching part, it is 
using IRFP460 [8].In the comparator circuit part, there areconsist of ICComparator IR2111 [9], and IC Optocoupler N250 of type. Last in $1^{\text {st }}$ floor, a power supply rectifier for converting uncontrolled AC to DC conversion.

\subsection{Induction Motor of Star-Connection}

The selector modes in modified algorithm, all switching strategies are available such as SPWM [1], and THIPWM [1], [3]. The R\&D purpose is toward an objective-based evaluation to reduce switch loss by following through two pillars, those are simulation and practice. In Figure 4, Our project work is under taken by merger preparation of the Individual Inverter.Our project work Representative of the First Inverter and the Second Inverter are a Regular Winding Induction Motor (RWIL) of Y-CIM. Also, an individual inverter in 2LC which using rules and regulations in three phase system of ELV as benchmarking in measurement of switch loss by using Power Harmonics Analyzer.The intention finally, reaching to the goal of Advanced Project Work in OEWSys category for the Open-End Winding Induction Motor (OEWIM) concept.

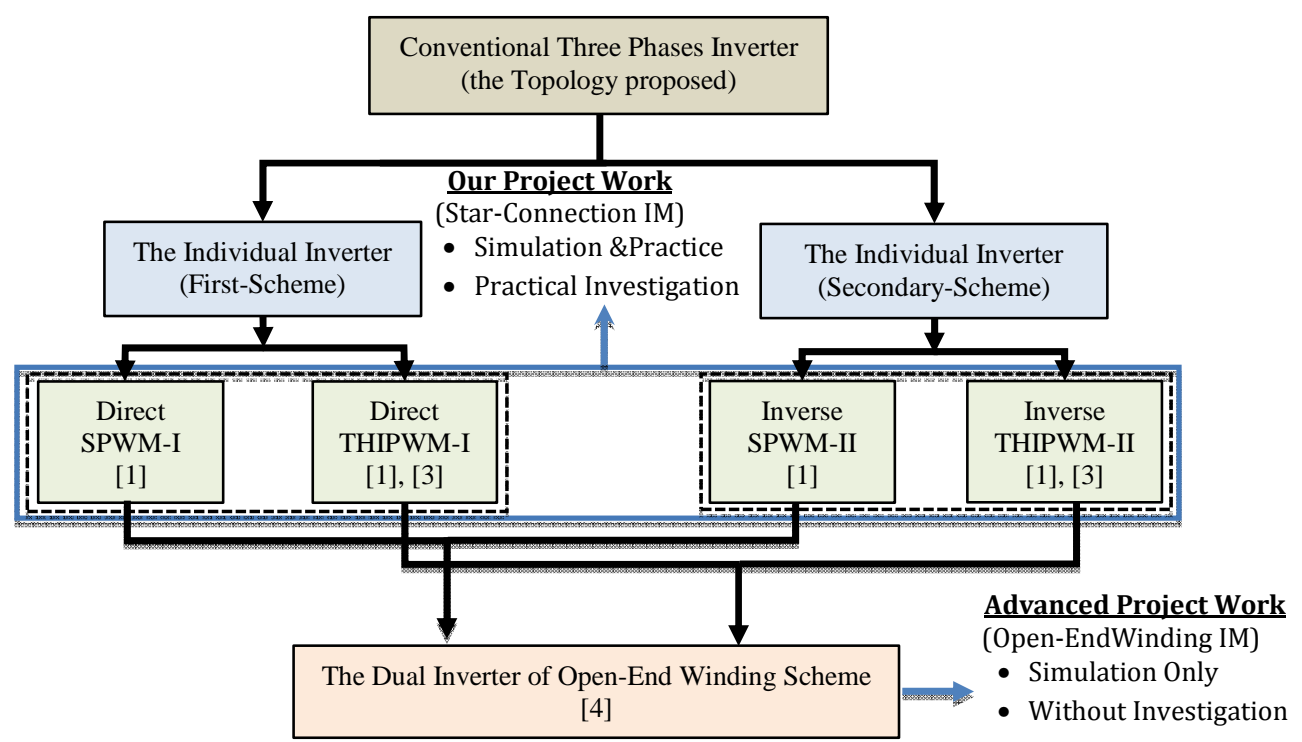

Figure 4. Complete Blok Diagramas the Part of Research

The individual inverter magnitude, 2LC voltage of Line to Neutral $\left(\mathrm{V}_{\mathrm{L}-\mathrm{N}}\right)$ with $\mathrm{U}_{\mathrm{uo}}, \mathrm{U}_{\mathrm{vo}}$, and $\mathrm{U}_{\mathrm{wo}}$ by $\mathrm{U}_{\mathrm{dc}} / 2 \mathrm{of}$ each single phase measurement from calculation. Thus, 2LC voltage of Line to Line $\left(\mathrm{V}_{\mathrm{L}-\mathrm{L}}\right)$ also $\mathrm{U}_{\mathrm{uv}}, \mathrm{U}_{\mathrm{vw}}$, and $\mathrm{U}_{\mathrm{wu}}$ by $\mathrm{U}_{\mathrm{dc}}$ of each two phases measurement from calculation. So, both of them are representing in voltage relation between $\mathrm{V}_{\mathrm{L}-\mathrm{N}}$ and $\mathrm{V}_{\mathrm{L}-\mathrm{L}}$ by Equation (1), (2), and (3) are given:

$$
\begin{aligned}
\mathrm{U}_{u v} & =\mathrm{U}_{u o}-\mathrm{U}_{v o} \\
\mathrm{U}_{v w} & =\mathrm{U}_{v o}-\mathrm{U}_{w o} \\
\mathrm{U}_{w u} & =\mathrm{U}_{v o}-\mathrm{U}_{u o}
\end{aligned}
$$


A two-phases system of alternating current flows on the rectifier circuit, and dc current with ripple is generated at the output of rectifier. The individual inverter (a direct inverter and inverse inverter are also used this configuration) in 2LC from Figure 5 can be generatedby SPWM, THIPWM, and SVPWM, by $\mathrm{u}+, \mathrm{v}+, \mathrm{w}+$ (upper switch) and $\mathrm{u}-, \mathrm{v}-, \mathrm{w}-$ (lower switch) are explain in the next point number by sub-point for each other technique.

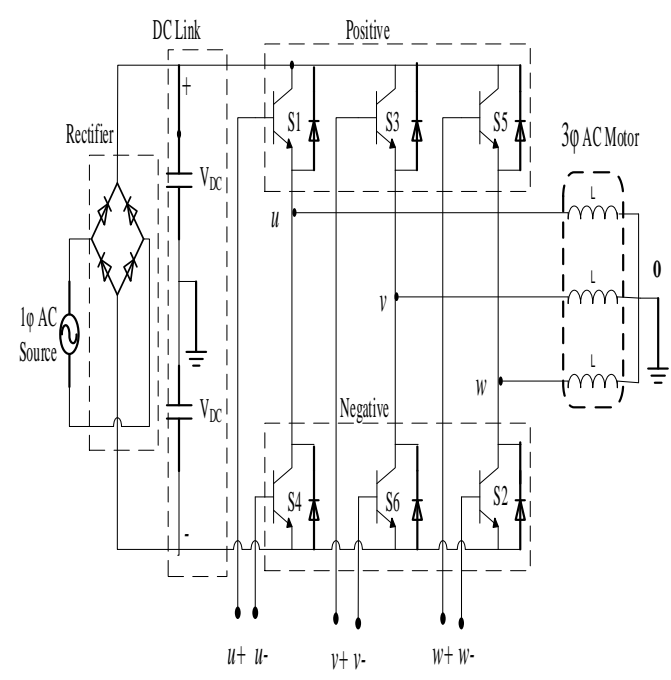

(a)

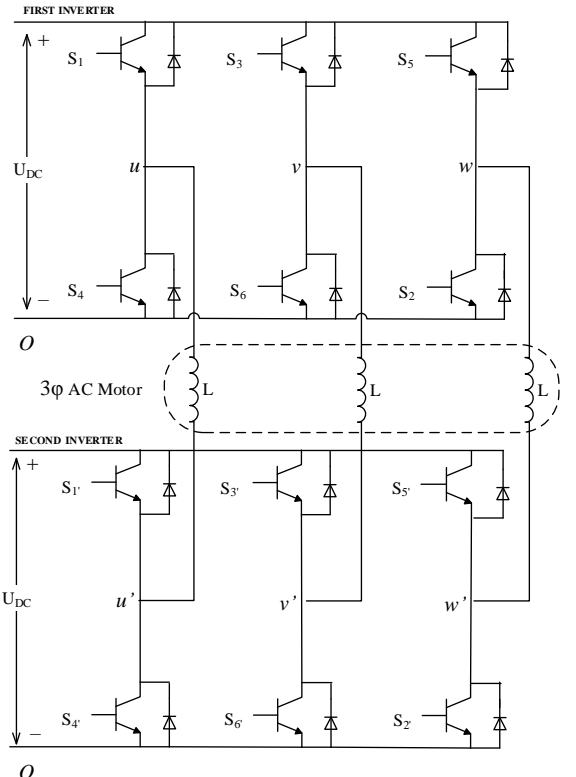

(b)

Figure 5.Scheme (a) Individual Inverterby using Star-Connection Induction Motor

(b) Dual Inverter by using Open-End Winding Induction Motor

From Figure 5(a) can be explained, that the power supply materials in common are including a phase source as the input rectifier circuit to the end of point in DC Link as the output, and to be the input of an individual inverter. For each phase degree of $\mathrm{u}, \mathrm{v}$, and $\mathrm{w}$ are separate in $360^{\circ}$ divided by the number of phases of each other in Equation (1) and the connection between Figure 5(b) in Equation (2) as follow:

$$
\begin{aligned}
& \mathrm{I}^{0}=360^{0} / \mathrm{n} \\
& \mathrm{U}_{\mathrm{DC}}=2 \times \mathrm{V}_{\mathrm{DC}}
\end{aligned}
$$

For $\mathrm{I}^{0}$ is the interval degrees and $\mathrm{n}$ is the total of phases. In three phases system, we find out of $u$ has the $0^{\circ}, v$ has $120^{\circ}$, and $w$ has $240^{\circ}$ respectively. This is becoming our basis in development to comparing with evaluation dual inverter.

\subsection{Load Preparation for the Converter}

The OEWSys Electrically Load for observation, a nameplate-usable has been arranged forsuitable to the three-phases Inverter and the three-phases induction motor (IM).Table 1 is the load of type B and also for bothmentioned 
of which is using induction motor with Resistance-Inductance (R-L) load for the output.

Table 1. Nameplate of Induction Motor Inductance-Resistance

\begin{tabular}{|l|l|}
\hline \multicolumn{1}{|c|}{ Discussion } & \multicolumn{1}{c|}{ Nominal/Type } \\
\hline Standard & $\begin{array}{l}\text { Motor: IEC 60034-1 } \\
\text { Current: IEC 60038 }\end{array}$ \\
\hline Type & A-Y3A 71M2-4 B3 \\
\hline Voltage & $220 / 380 \mathrm{~V}$ \\
\hline Rated Current & $1.9 / 1,1 \mathrm{~A}$ \\
\hline Power & $0.37 \mathrm{~kW}$ \\
\hline Cos phi & $75 \%$ \\
\hline Frequency & $50 \mathrm{~Hz}$ \\
\hline Speed & $1340 \mathrm{~min}^{-1}$ \\
\hline
\end{tabular}

Finally, the supply system for the power inverters can be seen in the Table 2,the Programmable Power Supply (PPS) usable.

Table 2. Characteristic ofProgrammable Power Supply

\begin{tabular}{|l|l|}
\hline \multicolumn{1}{|c|}{ Discussion } & \multicolumn{1}{c|}{ Nominal/Type } \\
\hline Supply system & $\mathrm{Vdc} \approx 198$ Volts. (6PS x 33Volts.) \\
\hline Rated Current & $\mathrm{I}_{\mathrm{dc}} \approx 3$ Amps. (6PS in Series $\cong$ 3Amps.) \\
\hline Switching Device & Voltage Source Inverter MOSFETs \\
\hline
\end{tabular}

\subsection{Induction Motor-Load}

On the next section, in Implementation is the regular winding induction motor (RWIM-Y) of implementation, a dual 2LC is shown in Figure 6.For examples, there are three classificationsfor Implementation. SPWM, THIPWM, SVPWM.Finally, the vital point of the power inverters can be seen in the explanation between application for power inverters data characteristic and crucial usable.

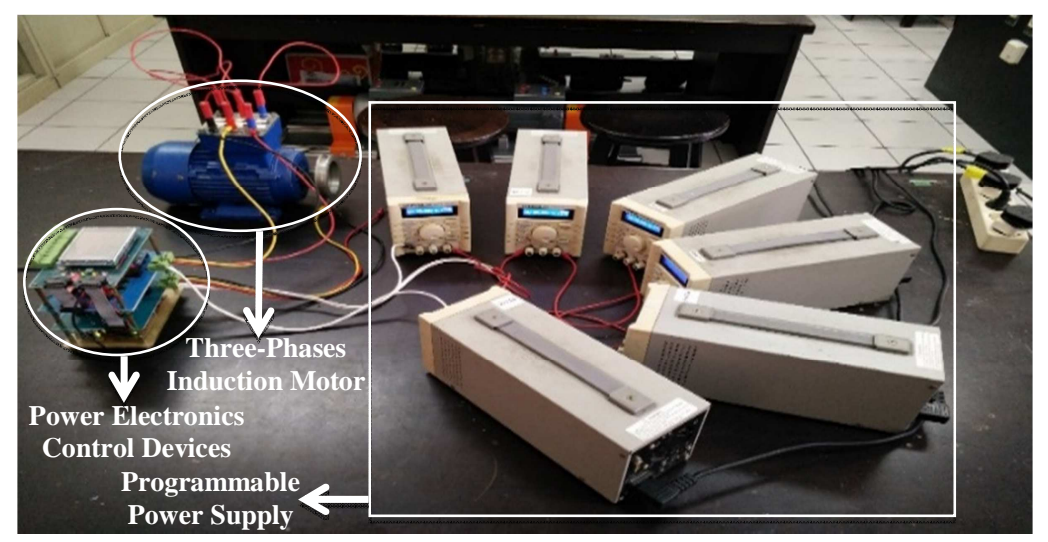

Figure 6. Configuration of the System Proposed 


\subsection{State of the ArtDecoupled SineRegular-Sampled}

Sine Regular-Sampled is the common $\mathrm{V} / \mathrm{f}$ constant technique in linear of Variable Voltage Variable Frequency (VVVF)drive so the called Sinusoidal Pulse Width Modulation (SPWM) by adjust of switching modulation PWM from comparator, by comparing First Inverter Modulating Signal (Va; Vb; Vc), Second Inverter modulating Signal (Vd; Ve; Vf), and Carrier Wave $\left(\mathrm{V}_{\mathrm{T}}\right)$ for the purpose of motor speed control. A switch control signal for the First Inverter could be regulation determined [1] by the following six-rules:

- $\mathrm{S}_{1}$ is $\mathrm{ON}$ and $\mathrm{S}_{4}$ is $\mathrm{OFF}$,when $\mathrm{Va}>\mathrm{V}_{\mathrm{T}}$ and then $\mathrm{V}_{u o}=0.5 \mathrm{Vdc}$ for Upper Switch in node $u$. (1 $1^{\text {st }}$ Rule)

- $\mathrm{S}_{4}$ is $\mathrm{ON}$ and $\mathrm{S}_{1}$ is OFF,when $\mathrm{Va}<\mathrm{V}_{\mathrm{T}}$ and then $\mathrm{V}_{v o}=-0.5 \mathrm{Vdc}$ for Lower Switch in nodev. (2 $2^{\text {nd }}$ rule)

- $\mathrm{S}_{3}$ is $\mathrm{ON}$ and $\mathrm{S}_{6}$ is $\mathrm{OFF}$, when $\mathrm{Vb}>\mathrm{V}_{\mathrm{T}}$, and then $\mathrm{V}_{v o}=0.5 \mathrm{Vdc}$ for Upper Switch in node $v$. ( $3^{\text {rd }}$ rule)

- $\mathrm{S}_{6}$ is $\mathrm{ON}$ and $\mathrm{S}_{3}$ is OFF, when $\mathrm{Vb}<\mathrm{V}_{\mathrm{T}}$, and then $\mathrm{V}_{w o}=-0.5 \mathrm{Vdc}$ for Lower Switch in node $w$. ( $4^{\text {th }}$ rule)

- $\mathrm{S}_{5}$ is $\mathrm{ON}$ and $\mathrm{S}_{2}$ is $\mathrm{OFF}$, when $\mathrm{Vc}>\mathrm{V}_{\mathrm{T}}$, and then $\mathrm{V}_{\text {wo }}=0.5 \mathrm{Vdc}$ for Upper Switch in node $w$. ( $5^{\text {th }}$ rule)

- $\mathrm{S}_{2}$ is $\mathrm{ON}$ and $\mathrm{S}_{5}$ is OFF when $\mathrm{Vc}<\mathrm{V}_{\mathrm{T}}$, and then $\mathrm{V}_{u o}=-0.5 \mathrm{Vdc}$ for Lower Switch in node $u$. (6 $6^{\text {th }}$ rule)

- $\mathrm{S}_{7}$ is $\mathrm{ON}$ and $\mathrm{S}_{10}$ is $\mathrm{OFF}$, when $\mathrm{Vd}>\mathrm{V}_{\mathrm{T}}$ and then $\mathrm{V}_{u^{\prime} o}=0.5 \mathrm{Vdc}$ for Upper Switch in node $u$. ( $7^{\text {th }}$ Rule)

- $\mathrm{S}_{10}$ is $\mathrm{ON}$ and $\mathrm{S}_{7}$ is OFF, when $\mathrm{Vd}<\mathrm{V}_{\mathrm{T}}$ and then $\mathrm{V}_{v^{\prime} o}=-0.5 \mathrm{Vdc}$ for Lower Switch in node $v$. ( $8^{\text {th }}$ rule)

- $S_{9}$ is $O N$ and $S_{12}$ is $O F F$, when $V e>V_{T}$, and then $V_{v^{\prime} o}=0.5 V d c$ for Upper Switch in node $v$. (9 $9^{\text {th }}$ rule)

- $\mathrm{S}_{12}$ is $\mathrm{ON}$ and $\mathrm{S}_{9}$ is OFF, when $\mathrm{Ve}<\mathrm{V}_{\mathrm{T}}$, and then $\mathrm{V}_{w^{\prime} o}=-0.5 \mathrm{Vdc}$ for Lower Switch in node $w$. (10 $10^{\text {th }}$ rule)

- $\mathrm{S}_{11}$ is $\mathrm{ON}$ and $\mathrm{S}_{8}$ is $\mathrm{OFF}$, when $\mathrm{Vf}>\mathrm{V}_{\mathrm{T}}$, and then $\mathrm{V}_{w^{\prime} o}=0.5 \mathrm{Vdc}$ for Upper Switch in node $w$. (11 $1^{\text {th }}$ rule)

- $\mathrm{S}_{8}$ is $\mathrm{ON}$ and $\mathrm{S}_{11}$ is $\mathrm{OFF}$ when $\mathrm{Vf}<\mathrm{V}_{\mathrm{T}}$, and then $\mathrm{V}_{u^{\prime} o}=-0.5 \mathrm{Vdc}$ for Lower Switch in node $u$. (12 $12^{\text {th }}$ rule)

A switch control signal for the Second Inverter, those are similar with the First Inverter but restricted for mutual connection to symbolized number in regulation-respect recognition. For the limited function, the equation for $S_{n+6}$ with $n=1, \ldots, 6$ of number of switching devices, etc.

\subsection{State of the Art Decoupled Fifth Harmonic Direct-Injection}

Harmonics can be generated by the addition of Fifth ( $\left.5^{\text {th }}\right)$ Harmonics Injection (FHIPWM) in phase waveform of the sinusoidal reference waveform. The addition of fifth harmonic component also improves the DC utilization of the inverter. But the effect in addition of the third harmonic component is reduction in the peak value of the resultant output voltage wave by a factor of 0.866 without any change in the fundamental input phase 
voltage of FHIPWMwaveforms with the triangular of 5000 NoS were applied in this technique.The formulae for modulating wave in this method is replaced $\omega t$ with $\theta$ as angle, Where and $A$ is a parameter to be optimized while keeping the maximum amplitude of $y(t)$ under unity. Solving Equation (5), the required waveformis presented by:

$$
U_{x}=\sin \theta+\frac{1}{10} \sin 5 \theta
$$

The $5^{\text {th }}$ harmonics passed through zero, at these values of $\theta$. Substitute the value of $\theta$ with $n \pi / 3$ of $\widehat{U}_{x}$ for the maximum amplitude at these angles. It is probably to increase the amplitude of the modulating waveform by a factor of $\mathrm{C}$ as Constanta so that the full output voltage range of the inverter is again used. If the modulating waveform is expressed in Equation (6) as follows:

$$
U_{x}=C\left(\sin \theta+\frac{1}{10} \sin 5 \theta\right)
$$

The factor $C=\frac{2}{\sqrt{3}}$ is a peak value of limit, where $C$ is a gain factor to increase the amplitude in the modulating waveform of the direct inverter by Equation (7), (8), and (9) of each by the following:

$$
\begin{aligned}
& U_{u o}=\frac{2}{\sqrt{3}}\left[\sin \theta+\frac{1}{10} \sin 5 \theta\right] \\
& U_{v o}=\frac{2}{\sqrt{3}}\left[\sin \left(\theta+120^{\circ}\right)+\frac{1}{10} \sin 5 \theta\right] \\
& U_{w o}=\frac{2}{\sqrt{3}}\left[\sin \left(\theta+240^{0}\right)+\frac{1}{10} \sin 5 \theta\right]
\end{aligned}
$$

For the inverse inverter, we used an equation by [1] andit has same with SPWM generating technique as follows:

$$
\begin{aligned}
& U_{u \prime o}=\frac{2}{\sqrt{3}}\left[\sin \left(\theta+180^{\circ}\right)+\frac{1}{10} \sin 5 \theta\right] \\
& U_{v^{\prime O}}=\frac{2}{\sqrt{3}}\left[\sin \left(\theta+300^{\circ}\right)+\frac{1}{10} \sin 5 \theta\right] \\
& U_{w^{\prime} O}=\frac{2}{\sqrt{3}}\left[\sin \left(\theta+420^{\circ}\right)+\frac{1}{10} \sin 5 \theta\right]
\end{aligned}
$$

This method is similar as direct inverter by using $3^{\text {rd }}$ harmonics of THIPWM, but in our operation is different at $5^{\text {th }}$ harmonics ofFHIPWM and also using inverse inverter for combination [3].

\section{EXPERIMENT AND ANALYSIS}

In essence, $n$-Level investigation which $n=2$ is useful by the following research conduct in prototyping device with measurement by laboratory 
settings that including equipment needs, this purpose also useful to compare waveform with the simulation result.

\subsection{Simulation and Practice with Practical Investigation of Y-CIM}

Refer to the study comparison,all techniques in Simulation and Practice with Practical Investigation is almost similar about the nominal of voltage because in extra-low voltage application and different in phase structure of voltage and current, the harmonic is also decrease. Then, several PWM patterns have been generated by ARM Cortex STM32F4 Discovery and this would be as controller unit optional such as additional trade-off besides FPGA and the other Microcontroller-Based Inverter. Some of greater notch appeared with the marker of dashed circle from the Osscilloscope.
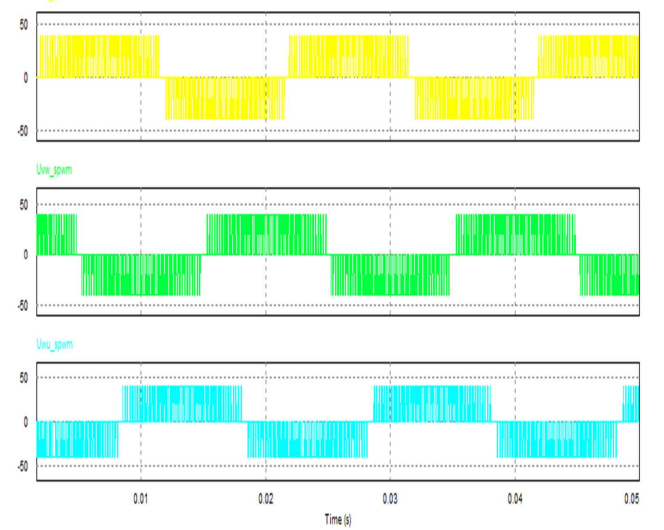

(a)

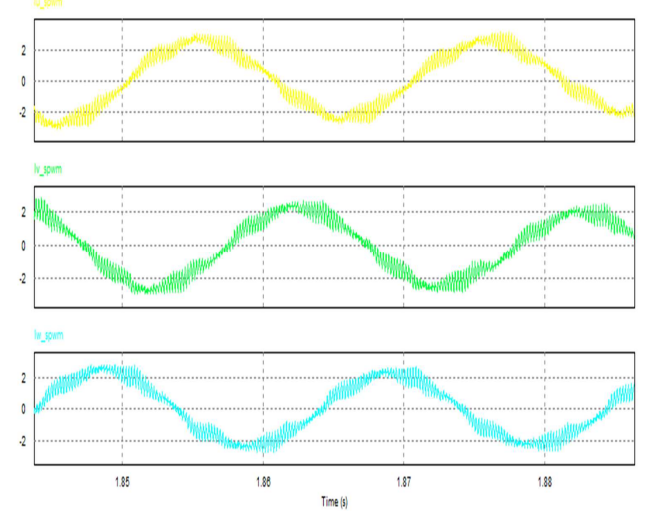

(c)

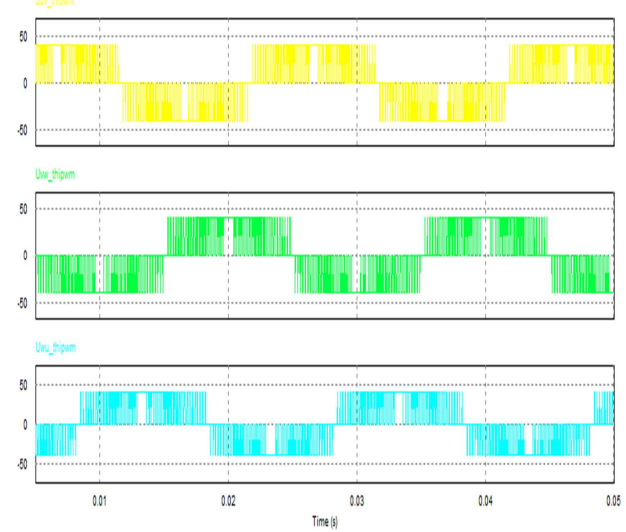

(b)

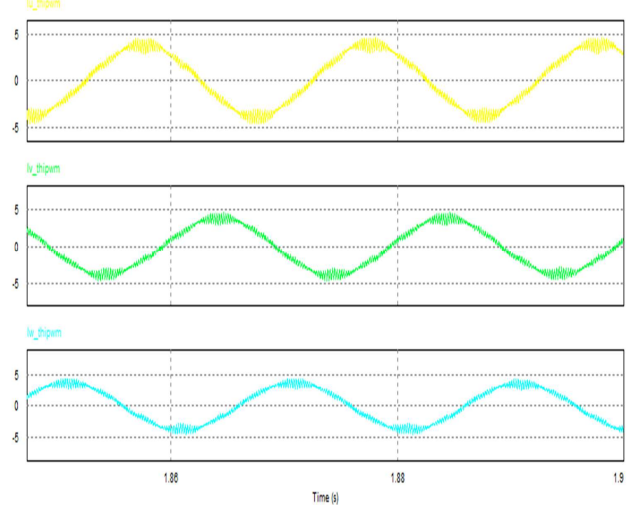

(d)

Figure 7. Simview Waveformsof YCIM (a) $\mathrm{V}_{\text {SPWM }}$ (b) $\mathrm{V}_{\text {FHIPWM }}$ (d) $\mathrm{I}_{\mathrm{SPWM}}$ (e) $\mathrm{I}_{\mathrm{FHIPWM}}$

For voltage of the Simview of YCIM, simulation in Figure 7(a) is technique of SPWM ( $\left.\mathrm{V}_{\text {SPWM }}\right)$ and Figure $7(\mathrm{~b})$ is technique of THIPWM ( $\left.\mathrm{V}_{\text {THIPWM }}\right)$. For current, simulation in Figure 7 (c) is technique of SPWM (ISPWM) and Figure $7(\mathrm{~d})$ is technique of THIPWM ( $\left.\mathrm{I}_{\text {THIPWM }}\right)$. 


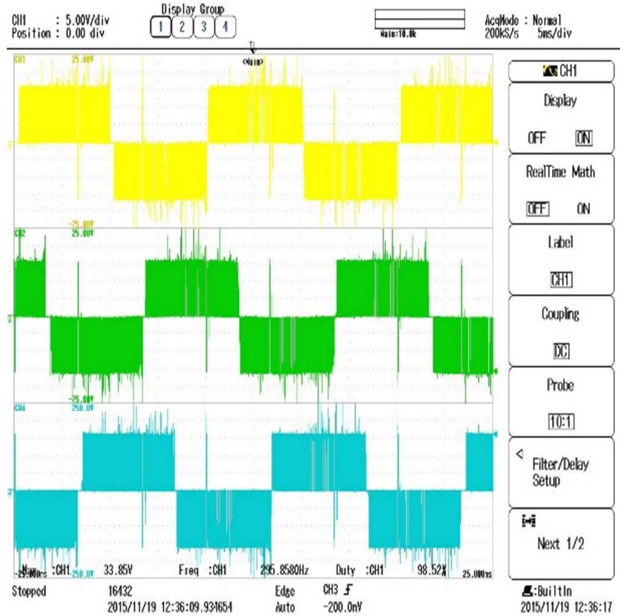

(a)

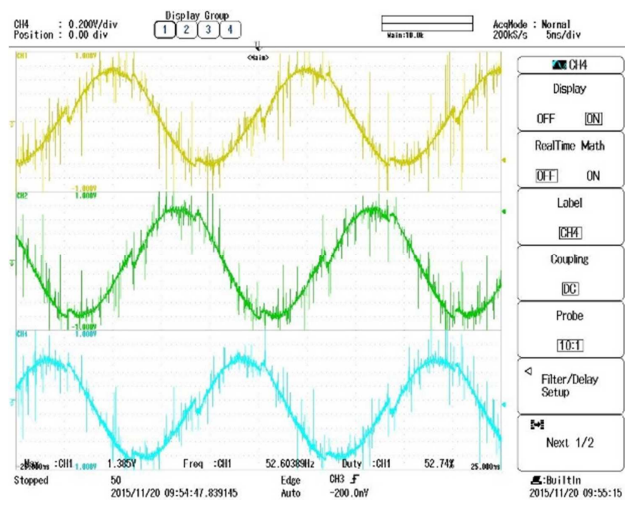

(c)

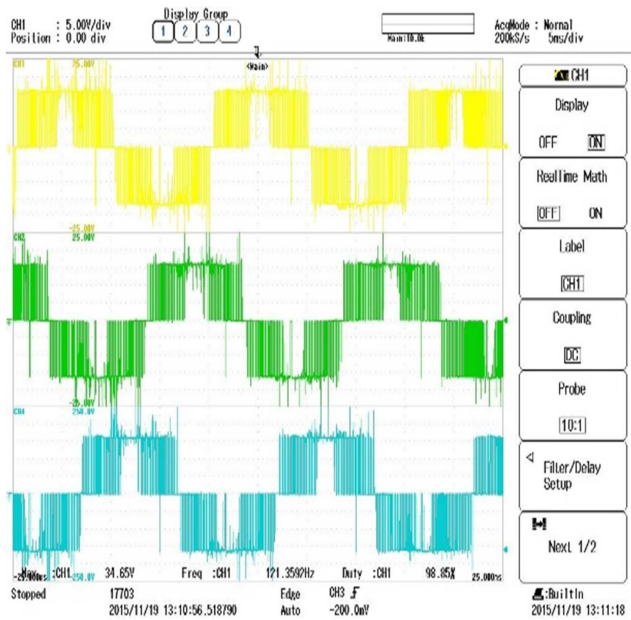

(b)

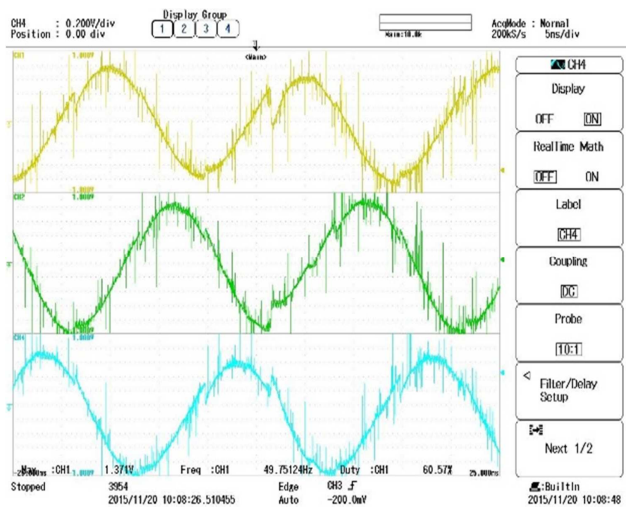

(d)

Figure 8. Oscilloscope Waveforms of First YCIM (a) $\mathrm{V}_{\text {SPWM-I }}$ (b) $\mathrm{V}_{\text {FHIPWM-I }}$

(c) $\mathrm{I}_{\text {SPWM-I }}(\mathbf{d}) \mathrm{I}_{\text {FHIPWM-I }}$

For voltage, simulation in Figure 8(a)is technique of SPWM (VSPWM-I $)$ and Figure $8(\mathrm{~b})$ is technique of FHIPWM $\left(\mathrm{V}_{\text {FHIPWM-I }}\right)$. For current, simulation in Figure $8(\mathrm{c})$ is technique of SPWM(ISPWM-I $)$ and Figure $8(\mathrm{~d})$ is technique of FHIPWM (IFHIPWM-I). Simview was shown by using IM load, each inverter in comparison with application is marking by voltage and current.One of the several importance of application, that is defining notch in the waveforms. Those notch are not appeared in the waveforms of each technique of [1] or it may be done by several parameters sets-up. In this case, an ELV with comparative study between ideal condition and real condition would be interesting for the further study.Our pre-Dual scheme by using STM32F4 Discovery is not restricted to giving a solution in which as complement and they have better performance because of it-self flexibilites and advantages in material-usable of the future work integration.One hand, there are massive voltage connection in the range of Extra-High Voltage to Medium-Voltage which has several precaution of damage influence in Grid-System. 


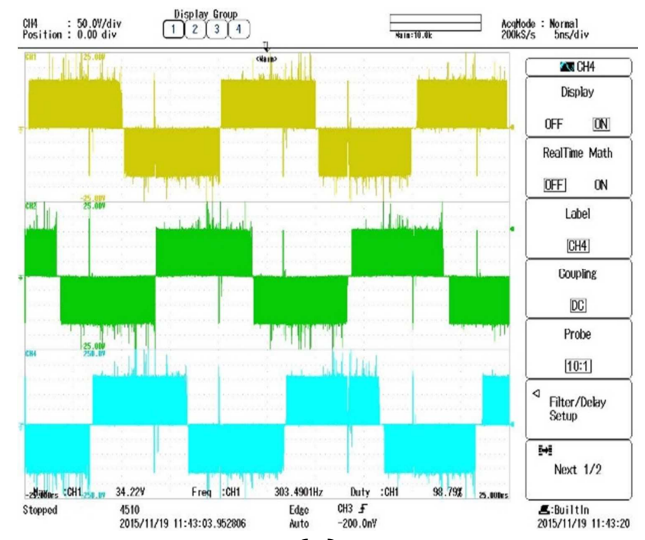

(a)

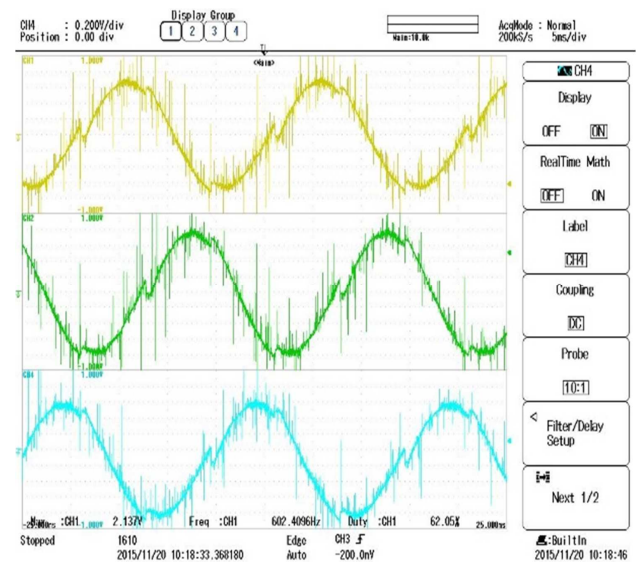

(c)

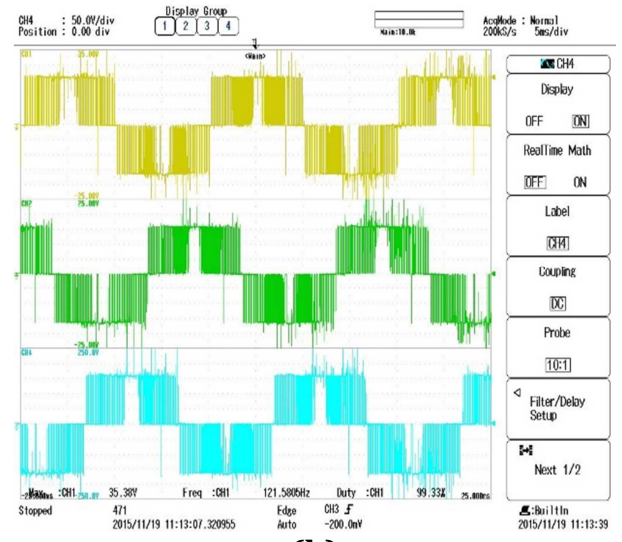

(b)

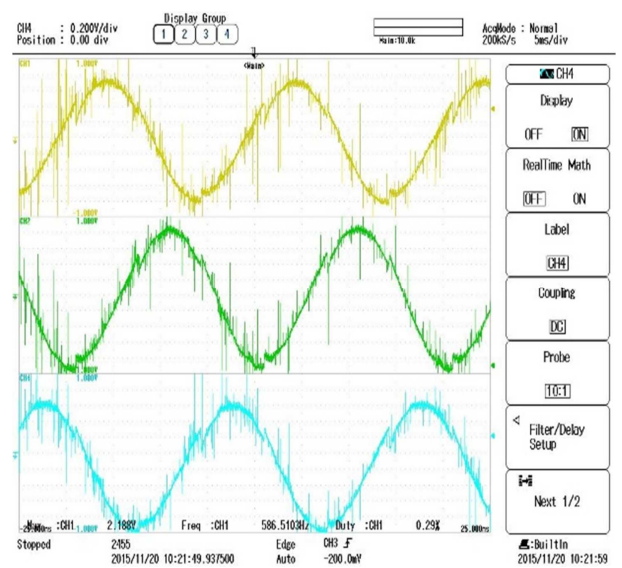

(d)

Figure 9. Oscilloscope Waveforms of SecondYCIM(a) $V_{\text {SPWM-II }}$ (b) $V_{\text {FHIPWM-II }}$ (c) $\mathrm{I}_{\text {SPWM-II }}(\mathbf{d}) \mathrm{I}_{\text {FHIPWM-II }}$

For voltage of the First YCIM, simulation in Figure 9(a) is technique of SPWM ( $\left.\mathrm{V}_{\text {SPWM-II }}\right)$ and Figure $9(\mathrm{~b})$ is technique of FHIPWM ( $\left.\mathrm{V}_{\text {FHIPWM-II }}\right)$. For current, simulation in Figure 9(c) is technique of SPWM (ISPWM-II) and Figure 9(d) is technique of FHIPWM (I $\mathrm{I}_{\text {FHIPWM-II }}$ ). An Oscilloscope display shown by using Induction Motor load of each inverter in implementation is marking by voltage and current.the Voltage Scope Measurement without electrically load added the Current Scope Measurement without mechanical load for the testing of THDv and THDi for the inverter which used to feed induction motor both in simulation and practical result.For clearly vision, one side is represented of high-notched and another side is represented of lownotched.The highest notched of current is the SPWM and the lowest notched is the SVPWM because has no notched.For the comparison between the practical test and the simulation design, the only distinguished found in Oscilloscope and Simview is about defining the notch in practical test, but in simulation design is in ideal structure which notch not found. 


\subsection{Simulation Only without Practical Investigation of OEWIM}

For the purpose of advance project work which mentioned,there is also demonstrate on terms and condition about the same treatment, the rules and regulations for [6] is not used because in state of simulation onlyin Figure 10 to be as prediction of waveform.

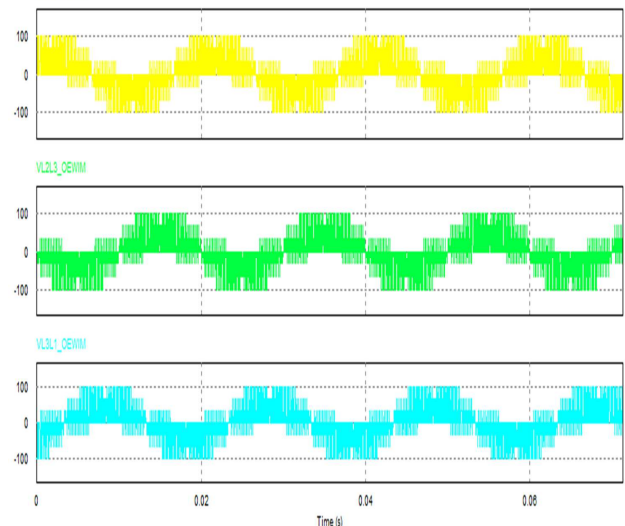

(a)

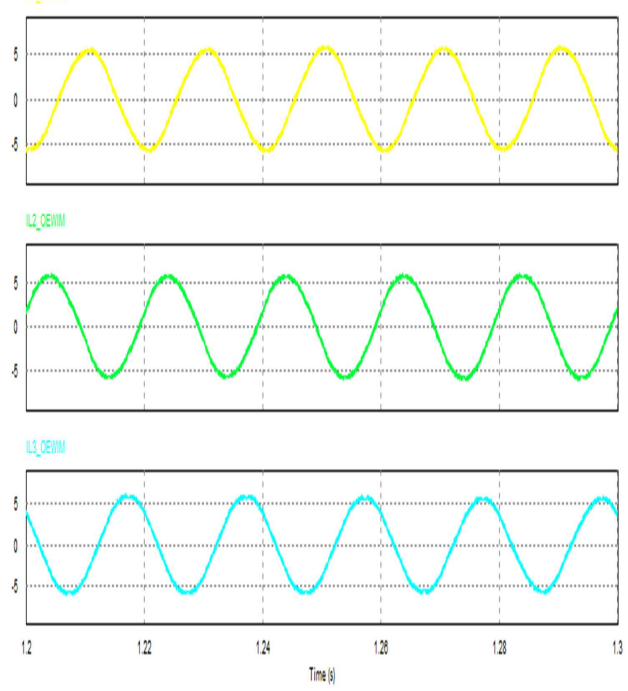

(c)

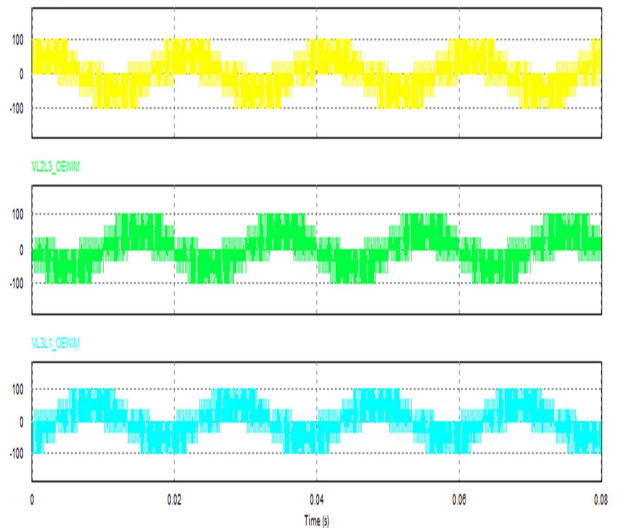

(b)

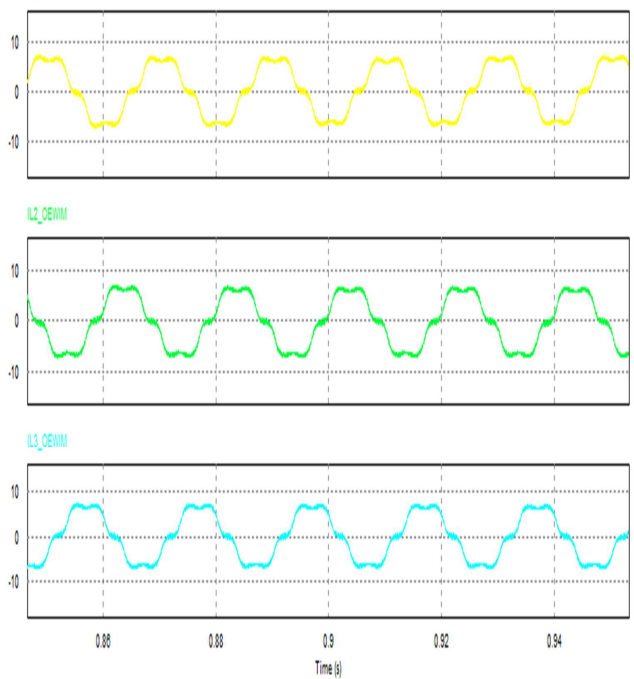

(d)

Figure 10. Simview Waveforms of $\operatorname{OEWIM(a)} \mathrm{V}_{\mathrm{dSPWM}}(\mathbf{b}) \mathrm{V}_{\mathrm{dFHIPWM}}$

(c) $\mathrm{I}_{\mathrm{dSPWM}}(\mathbf{d}) \mathrm{I}_{\mathrm{dFHIPWM}}$

For voltage of the OEWIM, simulation in Figure 10(a) is technique of Decoupled SPWM ( $\left.\mathrm{V}_{\mathrm{dSPWM}}\right)$ and Figure $10(\mathrm{~b})$ is technique of Decoupled FHIPWM (V $\left.\mathrm{V}_{\mathrm{dFHIPWM}}\right)$. For current, simulation in Figure $10(\mathrm{c})$ is technique of Decoupled SPWM (I $\left.\mathrm{I}_{\mathrm{dSP}} \mathrm{m}\right)$ and Figure $10(\mathrm{~d})$ is technique of Decoupled FHIPWM (I $\mathrm{I}_{\mathrm{dFHIPWM}}$ ).Finally, Both Direct Inverter and Inverse Inverter are considered to the ELV successor of 2LC supply system to the rest of defining low risk on Synergy Preparation for authentication in applied research and also the simulation for comparative study. 


\subsection{The Results}

In this research investigation, the techniques are membership into four PWM. Those are conventional SPWM, Conventional FHIPWM, Decoupled SPWM, and Decoupled FHIPWM. In the contex after conducting research, the data collect in the Table 3 is representing of all examination about SPWM, and FHIPWM. Of course, all in the ELV experimental application. This is separately in Techniques, type of inverter, Practical Test Parameters of Voltage and Current, and the Total Harmonic Distrtion of Voltage and Current are represented to be review with IEEE 519 standard [7] of Simulation Design.

Table 3. The Result with treatment for $\mathrm{V}_{\text {inverter }}<50$ Volt

\begin{tabular}{|c|c|c|c|c|c|}
\hline \multirow[t]{2}{*}{ Techniques } & \multirow[t]{2}{*}{ Inv. } & \multicolumn{2}{|c|}{$\begin{array}{l}\text { Waveform Data } \\
\text { (Practical Test) }\end{array}$} & \multicolumn{2}{|c|}{$\begin{array}{l}\text { Total Harmonic Distortion } \\
\text { (Simulation Design) }\end{array}$} \\
\hline & & Voltage & Current & Voltage & Current \\
\hline \multirow{2}{*}{$\begin{array}{l}\text { Conventional } \\
\text { SPWM }\end{array}$} & I & $33.85 \mathrm{~V}$ & $1.385 \mathrm{~A}$ & \multirow{2}{*}{$\begin{array}{l}7.2726051 \mathrm{e}-001 \\
\text { (Simview proof) }\end{array}$} & \multirow{2}{*}{$\begin{array}{l}2.2714862 \mathrm{e}-001 \\
\text { (Simview proof) }\end{array}$} \\
\hline & II & $34.22 \mathrm{~V}$ & $2.137 \mathrm{~A}$ & & \\
\hline \multirow{2}{*}{$\begin{array}{l}\text { Conventional } \\
\text { FHIPWM }\end{array}$} & I & $34.65 \mathrm{~V}$ & $1.371 \mathrm{~mA}$ & \multirow{2}{*}{$\begin{array}{l}5.7262473 \mathrm{e}-001 \\
\text { (Simview proof) }\end{array}$} & \multirow{2}{*}{$\begin{array}{l}\text { 9.8587721e-002 } \\
\text { (Simview proof) }\end{array}$} \\
\hline & II & $35.38 \mathrm{~V}$ & $2.188 \mathrm{~mA}$ & & \\
\hline $\begin{array}{l}\text { Decoupled } \\
\text { SPWM }\end{array}$ & I, II & $\begin{array}{c}- \\
\text { (Concept) }\end{array}$ & $\begin{array}{c}- \\
\text { (Concept) }\end{array}$ & $\begin{array}{l}4.6552717 \mathrm{e}-001 \\
\text { (Simview proof) }\end{array}$ & $\begin{array}{l}\text { 1.4817903e-002 } \\
\text { (Simview proof) }\end{array}$ \\
\hline $\begin{array}{l}\text { Decoupled } \\
\text { FHIPWM }\end{array}$ & I, II & $\begin{array}{c}- \\
\text { (Concept) }\end{array}$ & $\begin{array}{c}- \\
\text { (Concept) }\end{array}$ & $\begin{array}{l}3.2043740 \mathrm{e}-001 \\
\text { (Simview proof) }\end{array}$ & $\begin{array}{l}\text { 1.6492202e-002 } \\
\text { (Simview proof) }\end{array}$ \\
\hline
\end{tabular}

From the Display of Voltage Measurement result, a Simview of simulation Circuit and an Ossciloscope of practical application are both have the mutual waveform at voltage phase structure, and current phase pattern between SPWM, FHIPWM, decoupled SPWM, and decoupled FHIPWM. Moreover, refer to this context, the scope of both waveforms has been validated. The comparative study goal, it tends by each measurement of the following statement:

- For the Practical test, aVoltage Line-to-Line $\left(\mathrm{V}_{\mathrm{L}-\mathrm{L}}\right)$ is used by measuring technique of peak-to-peak $\left(\mathrm{V}_{\mathrm{p}-\mathrm{p}}\right)$ of root-meansquarevoltage by the way $\left(\mathrm{V}_{\text {rms-SPwM }} \approx \mathrm{V}_{\text {rms-FHIPWM}}\right)$.

- Also, a Current Line-to-Line ( $\mathrm{I}_{\mathrm{L}-\mathrm{L}}$ ) by measuring technique of peak-topeak $\left(\mathrm{I}_{\mathrm{p}-\mathrm{p}}\right)$ of root-mean-square by the result ( $\left.\mathrm{I}_{\mathrm{rms}-\mathrm{SPWM}}>\mathrm{I}_{\text {rms-FHIPWM }}\right)$.

- For the Simulation Design of THDv from Simview proof, THDV of Conventional SPWM $>\mathrm{THD}_{\mathrm{V}}$ of Conventional FHIPWM.THDV of Conventional SPWM $>\mathrm{THD}_{\mathrm{V}}$ of Decoupled SPWM. THDV of Conventional FHIPWM $>\mathrm{THD}_{\mathrm{V}}$ of Decoupled FHIPWM. THD of Decoupled SPWM $>$ THD $_{\mathrm{V}}$ of Decoupled FHIPWM.

- Another proof of $\mathrm{THD}_{\mathrm{I}}$ in Simview, $\mathrm{THD}_{\mathrm{I}}$ of Conventional SPWM > $\mathrm{THD}_{\mathrm{I}}$ of Conventional FHIPWM. THD I of Conventional SPWM $>\mathrm{THD}_{\mathrm{I}}$ of Decoupled SPWM. THD I of Conventional FHIPWM $>\mathrm{THD}_{\mathrm{I}}$ of 
Decoupled FHIPWM. THD I of Decoupled SPWM $<$ THD I of Decoupled FHIPWM.

\section{CONCLUSION}

From the practical test, the root-mean-square voltage of both voltage and current measurements have no change in voltage because in ELV configuration, and that indicates a current consume in SPWM technique, in another way it was reduced in FHIPWM technique.

In the simulation design,there are Simview display for investigation to the nominal of THDv and THDi result which has in better performance for the combination of dual converter than the standalone of individual converter.

Finally, the Individual Inverter by YCIM and the Dual Inverter by OEWIM compares with the THDv and THDi standard of IEEE 519 in whichindicates that our result is in linewith the criterion, and also the Simview proof forDual Inverter is given the better performance in Total Harmonic Distortion.

\section{Acknowledgements}

The first author is gratefully thanks to the Electronics Engineering Polytechnic Institute of Surabaya for the Scholarship.

\section{REFERENCES}

[1] Z. B. Ibrahim, Md. L. Hossain, I. B. Bugis, N. M. N. Mahadi, Ahmad Shukri Abu Hasim, Simulation Investigation of SPWM, THIPWM and SVPWM Techniques for Three Phase Voltage Source Inverter, International Journal of Power Electronics and Drive System (IJPEDS), Vol. 4, No. 2, June 2014, pp. 223 232, ISSN: 2088-8694.

[2] ..........., STM32F4DISCOVERY, Discovery kit with STM32F407VG MCU, DocID022204 Rev 5, STMicroelectronics, 2016.

[3] I. Colak, R. Bayindir, E. Kabalci,A Modified Harmonic Mitigation Analysis Using Third Harmonic Injection PWM in a Multilevel Inverter Control, IEEE 14th International Power Electronics and Motion Control Conference(EPE-PEMC), pp. T2-215 - T2-220,2010.

[4] E. G. Shivakumar, K. Gopakumar, S. K. Sinha, A. Pittet, V. T. Ranganathan, Space Vector PWM Control of Dual Inverter FedOpen-End Winding Induction Motor Drive, The Sixteenth Annual IEEE Applied Power Electronics Conference and Exposition,Anaheim, CA,Vol. 1, pp. 399-405, 2001.

[5] M. Schweizer, T. Friedli,J.Kolar, Comparative Evaluation of Advanced Three-Phase Three-Level Inverter/Converter Topologies AgainstTwo-Level Systems, IEEE Transactions on Industrial Electronics, Vol. 60 no. 12, pp. 5515-5527, 2013. 
[6] ..........., Code of Practice for the Electricity (Wiring) Regulations, Electrical and Mechanical Services Department, Hong Kong, 2015.

[7] T. Hoevenaars, K. LeDoux, M. Colosino, Interpreting IEEE Std 519 and Meeting its Harmonic Limits in VFD Applications, The 50th IEEE Annual Conference on Industry Applications Society, Houston, TX, USA, pp. 145-150, 2003.

[8] SMPS MOSFET

IRFP460APower MOSFET,PD91880International Rectifier, USA, 1999.

[9] ..........., IR2111 HALF-BRIDGE DRIVER, Data Sheet No. PD-6.028C of Control Integrated Circuit Designers Manual International Rectifier, USA. 